\title{
Research on How to Improve Employee Performance with Performance Pay \\ Liqin $\mathrm{Li}^{1, \mathrm{a}}$ \\ ${ }^{1}$ Xi'an International University, Xi'an, Shaanxi, China, 710077 \\ aemail,
}

Keywords: Performance Pay, Employee Behavior, Expectation Theory

Abstract. Performance pay is often used to link performance and pay, with the aim of motivating employees to work better. This paper explains the impact of performance compensation on employee behavior from both the reinforcement theory and the expectation theory, and puts forward some requirements for the effective use of performance compensation to motivate employees and improve employee performance.

\section{Introduction}

Salary as a direct expression of money, in motivating employees to improve staff performance occupies a very important position. If you stand on the firm's position, employees hire employees to pay staff salaries, the purpose is to obtain performance, and finally to achieve business profits and goals. The relationship between pay and performance is the same as that of a coin, and the pay is not long. If there is no pay, the performance is difficult to sustain.

\section{What Is Performance Pay}

Pay-related performance (PRP) is a kind of salary management system which is popular with the performance management system in recent years. It is also regarded as an integral part of the organization's incentive plan. In general, performance is the contribution of the unit to the organization within a given time. The unit can be an individual or a group. Remuneration is the amount of income that is obtained by the employee's labor in the organization. Tangible services and benefits, that is, the organization must pay the human capital. Therefore, the so-called performance pay, refers to the staff salaries with individual, team or organizational performance of some of the measured changes in the variable pay changes, it highlights the performance of employees on their income level.

From the definition of performance pay, we can see that performance pay is actually an agreement between the business and the staff: you do well, the business will be responsible to you, will reward you, employees have the opportunity to share the business success Fruit, but both sides need to bear the corresponding risks. In other words, "your reward is what you deserve." Therefore, the performance pay is not only the recognition of the contribution of staff and return, or the strategic value of the enterprise into a specific action plan, and then form a consistent, common to achieve business goals, motivate staff initiative, sense of responsibility and sense of value. This is also the meaning of pay for performance. On the other hand, the performance pay is actually a typical combination of carrots and sticks: to stimulate the future behavior towards the enterprise in the direction of development. Therefore, the performance of pay is a focus on the future, the new pay concept.

\section{The Impact of Performance Compensation on Employee Behavior}

A reporter went to a small toy company to visit and found that the work environment where the small and messy, but the staff are still doing the work of the hands of concentrate. Even if no one next to the care, it is still the case. Reporters are wondering. The manager of the company explained: "The most important one: the detailed procedures for the preparation of a clear amount of 
compensation, every day doing bad, much less, very simple, the staff's heart is also clear.

Although the situation in this case was somewhat like Frederick Taylor's piece-rate system used to solve the "organized sabotage" phenomenon in the late nineteenth century, it is undeniable that the role of this incentive is obvious: employees in order to get paid, to meet the needs, will consciously improve their performance behavior to achieve the goal.

In human resources management, pay in order to give full play to their own role, should achieve two basic functions, one is the health function, one is the incentive function. The so-called health care function is to maintain the basic income of employees and the basic life of the function, the performance of basic wages and wages together with the benefits, allowances, etc., to eliminate the employee's dissatisfaction; incentive function is to mobilize the enthusiasm of the staff, enthusiasm And the role of incentives, the general performance of the work with the company and its employees linked to the incentive performance of the reward, used to stimulate the enthusiasm of the staff to improve employee satisfaction. If a company's salary only played its health function, did not play the incentive function, hope to get good performance is unrealistic. Because a good incentive is usually seen as a tool to inspire and guide employee behavior, performance pay will link the results of performance management to the returns that people get, which will undoubtedly make performance management and pay better effect. The effect of performance pay on employee behavior can be explained by reinforcement theory and expectation theory.

The Reinforcement Theory. Skinner's "theory of reinforcement" that people in order to achieve a certain purpose, will take a certain role in the environment. When the consequences of this act are favorable to him, this behavior will recur in the future; on the contrary, this behavior will be weakened or disappeared. People can use this positive or negative reinforcement approach to influence the consequences of behavior, thereby correcting their behavior. Thus, reinforcement theory can be applied to incentives and the transformation of human behavior. In terms of remuneration, Song Dyke's law of the law points out that the kind of paid response is more likely to recur in the future. Thus, combining this law with the reinforcement theory, we can clearly see the effect of performance pay on employee behavior: if higher-performing employees receive a corresponding higher pay return, they are more likely to meet in the future higher performance level. Correspondingly, if the higher performance does not receive the appropriate return and this performance level in the future again the possibility of not too much.

The Expectation Theory. Fromm's theory of expectation argues that an employee's behavior will be affected by three important variables: 1. Expectation (E) refers to incentives that have a certain intensity to motivate employees to work towards the chosen goal 2 . The tool value (I), when the desired level of performance is achieved, obtains the subjective probability of the required reward, the individual's judgment or the estimated reward; 3. The reward premium (V), refers to the target after the reward obtained in the minds of the relative value of the size of the parties. The motivation of a person to make a certain behavior (incentive intensity) is the product of $\mathrm{E}, \mathrm{I}, \mathrm{V}$ three variables, that is, $\mathrm{M}=\mathrm{E} \times \mathrm{I} \times \mathrm{V}$. The expected incentive mode is shown in Figure 1:

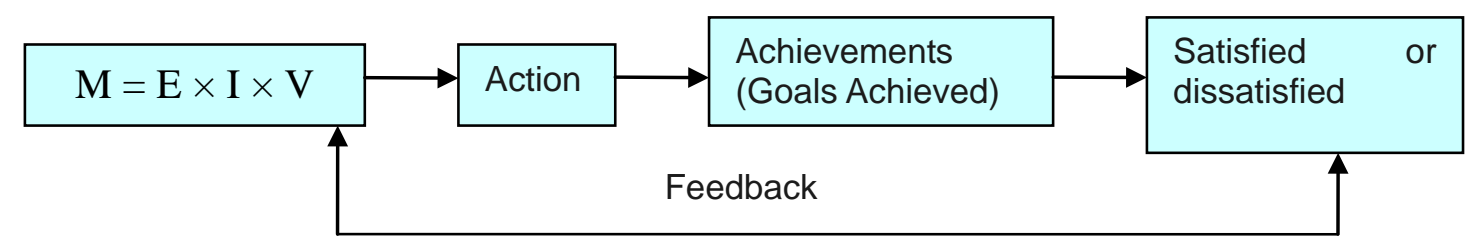

Figure 1 Expectation incentive pattern

The expectation theory suggests that the intensity of a behavioral bias depends on the desired intensity of the individual's outcome of a behavior and the attraction of the result to the actor. When employees think that hard work can get a good performance evaluation results, and good performance evaluation results can bring the need to meet the needs of the return, he will tend to pay more effort. Therefore, from the expectation theory we can draw the assumption that raising the level of remuneration resulting from the corresponding performance level will enhance the employee's motivation to improve performance. A large number of empirical studies have also confirmed the positive link between performance pay and performance (Jenk-ins, 1998). 


\section{How to Use Performance Compensation to Improve Staff Performance}

To make performance pay to play the role of incentives, and continuously improve staff performance, business managers in the design and implementation of performance compensation process should grasp the following requirements:

The Fairness Principle. Enterprises in order to attract, encourage and retain the ability of employees, with their wisdom to improve organizational performance, we must strive for the fairness of performance pay. There are two elements of equity here, one is the relative fairness between the internal staff, between the post and the post; the other is the external fairness, that is, the comparison between the pay and the external market price. In the enterprise, most employees are concerned about both internal and external pay. The internal consistency and external fairness of the pay system are important issues related to the sense of employee's sense of fairness and satisfaction. The implementation of performance pay often leads to the impact of the existing balance system. Therefore, the enterprise should pay the employee's salary with the external and internal average the relationship between the judge, if the salary has reached a high level, companies can be under the same conditions and adjust the salary range of employees, in order to control costs to maintain the overall balance of the pay system.

Correctly Grasp the Diversification of Staff Needs Level. According to the management master Maslow's theory of demand hierarchy, human needs are diversified and hierarchical. At the low-income level, they are most concerned about the increase in the amount of labor income and the increase in the absolute amount; and those high-income employees, they get mutual recognition of the remuneration, the focus will be transplanted to other aspects, such as the ability to display the space, the degree of respect for leadership trust and so on. This requires managers in the design of performance pay system, pay attention to the unity of material and spiritual compensation. It is necessary to meet the different needs of different levels of staff, but also to use the effort in the "survival needs" outside the higher level of demand. Only learn to differentiate the needs of different levels of staff, in order to "right medicine", a good performance of the performance of pay support and incentive function.

Performance Pay Is Consistent with the Development Strategy of the Enterprise. Performance pay should be closely linked to the corporate strategy to reward those employees who have successfully completed their corporate performance or behavior in line with the company's goals. In other words, the performance pay from the date of development, we must focus on the future, based on corporate strategy, the performance of the company's business strategy and tasks linked, is a pre-incentive, rather than a post-incentive. In order to make performance pay better for the strategic objectives of the enterprise, the employee behavior encouraged by performance pay should revolve around the key success factors of the firm. For example, for an enterprise that wants to lead the market trend, performance pay should enable companies to better motivate those who are adventurous and have the spirit of learning. For companies that want to compete by reducing their production costs, performance pay rewards should be rewarded for actions that increase operational efficiency or reduce costs. Enterprises can choose the appropriate performance pay system to support the corporate strategy, so that the behavior of employees and enterprises advocated by the behavior consistent.

The Relevance and Consistency between Performance and Pay. Both the theory of reinforcement and the theory of expectation tell us that only a clear correlation between performance and pay can make the performance pay really motivated. Through the establishment of the correlation between performance and pay, enterprises can use performance management to guide the behavior of employees, so that the behavior of employees is conducive to the realization of the company's goals. At the same time, to avoid performance pay as a simple "reward or punishment" tool, performance pay must maintain three aspects of consistency: the objectives of the staff and their corporate characteristics (the company's clients who? What are the company's products and services? ), The company's strategic planning (how the company fulfills its strategic mission) and the company's goals (what goals the company has established). In other words, at the beginning of performance pay, it is necessary for employees to identify what employees need to 
reward (to promote the company's goals), what are the actions to be punished (hindering the company's goal or affecting customer satisfaction) The Otherwise, purely for the "bonus penalty" thinking to manipulate the performance of pay, it will leave staff performance pay is actually "from an employee who spent money to another company's practice," one-sided understanding, and then Bring satisfaction to the decline. Finally, because managers are reluctant to offend subordinate employees, the average payment of the majority, the so-called performance pays nothing.

Performance Pay Is Based on Sound Performance Management. The biggest challenge in building and using performance pay systems is to quantify and evaluate job performance factors, that is, to accurately assess whether employees' goals are met. In fact, the establishment of performance pay is not difficult for the enterprise, provided that the performance and results are easy to see and quantify, such as sales, there is a very clear sales-oriented. But the non-sales department is not so easy, there will be a lot of resistance, how to quantify and evaluate is a problem, which involves the accuracy of performance evaluation issues. Therefore, in this sense, the implementation of performance pay must be based on the enterprise has a relatively perfect performance management system, including the realization of a relatively quantitative assessment management. For example, in the case of a customer relationship call center, the manager records the number of times each employee processes the call and the length of the process and investigates the level of customer satisfaction. According to these can be quantified results to assess, and then the results directly linked to the call center staff salaries.

In addition, as a management tool to improve performance, performance pay itself is not static. It is always with the development of enterprises, internal and external changes in the environment and constantly changing, with the adjustment of corporate strategic objectives and constantly adjust. Managers must always grasp the "pay" situation in order to better performance pay into performance management, so that employees with good "pay" for the company to create high value. For example, in a high-tech information technology company, the existing front-line sales staff wage structure is: basic salary + sales commission (performance pay). When the market situation is very good, the company has enough commission to encourage employees to increase sales. However, when the demand for products and services is shrinking and business returns are declining, salespeople are no longer as concerned about personal performance as they did in the past, and performance evaluations became formalism and perfection Performance pay has become a display. At that time, the company should re-examine the new market conditions, sales staff to design a new wage structure.

In short, changes in performance pay will lead to employee ideas, focus on changes in the object, through the "work effort - high performance - valuable return - wage satisfaction - work effort" expectations chain and value chain effective Cycle and unity, performance pay can play a role in encouraging employees to work hard to obtain high performance returns, and have a positive role in promoting corporate reform. Of course, the concept of performance pay is also relatively new in China, how to strengthen the incentive to maximize the pay leverage to stimulate the work of the enthusiasm of the staff, and the establishment of an effective performance pay system to motivate employees and improve the overall business performance, the final To achieve the core competitiveness of enterprises to enhance, will be actively involved in the salary management staff to explore a long and arduous task.

\section{References}

[1] Fang Zhenbang. Strategic Performance Management (Second Edition) [M]. Beijing: China University of Fine Arts Press, 2007:25-26

[2] Jin Guantao. Performance: Let your employees work for efficiency [M]. Beijing: Mechanical Industry Press, 2004:50-52

[3] Zhang Yong, Long Lirong. Performance compensation on team members to explore the behavior and the use of behavior [J]. Management Science, 2013, 5(3):45-48.

[4] Yang Weiguo, Wen Yanrui. Foreign public sector pay reform: background, mode and effect [J]. Journal of National School of Administration, 2011,8(1):21-25. 
[5] Liu Min. Three Misunderstandings of Performance Pay [J]. Human Resource Development, 2007, 8(1):62-67.

[6] Zou Man. Performance Compensation Overview [J]. Management Manager, 2010, 11(8):52-55. 